\title{
OPTIMALISASI DOSIS PROBIOTIK TERHADAP LAJU PERTUMBUHAN DAN KELANGSUNGAN HIDUP IKAN NILA (Oreochromis niloticus) PADA SISTEM BIOFLOK
}

\author{
Optimalization of Probiotic Doses on the Growth and Survival Rates of Nile Tilapia \\ (Oreochromis niloticus) in Biofloc System
}

Suprianto $^{1}$, Endah Sri Redjeki ${ }^{1}$ dan Muh. Sulaiman Dadiono ${ }^{1}$

${ }^{1}$ Program Studi Budidaya Perikanan, Fakultas Pertanian, Universitas Muhammadiyah Gresik, Gresik

*suprianto898@rocketmail.com

Abstrak

Ikan nila merupakan komoditas ikan bernilai ekonomi tinggi. Intensifikasi budidaya ikan nila berdampak kurang baik terhadap lingkungan. Tingginya penggunaan pakan buatan menyebabkan pencemaran perairan. Salah satu cara mengurangi penggunaan pakan buatan adalah dengan sistem bioflok. Penelitian ini bertujuan menganalisis dosis optimal probiotik terhadap laju pertumbuhan dan kelangsungan hidup ikan nila pada sistem bioflok. Metode yang digunakan adalah Rancangan Acak Kelompok (RAK) dengan 4 perlakuan dan 3 ulangan. Penambahan dosis probiotik $\mathrm{P}_{1}(0,007 \mathrm{ml} / \mathrm{l}), \mathrm{P}_{2}(0,008 \mathrm{ml} / \mathrm{l}), \mathrm{P}_{3}(0,009 \mathrm{ml} / \mathrm{l})$, dan Kontrol $(0 \mathrm{ml} / \mathrm{l})$ sebagai perlakuan. Bobot mutlak, panjang mutlak, dan kelangsungan hidup ikan nila sebagai variabel utama. Analisis polynomial orthogonal digunakan untuk menentukan dosis optimal probiotik. Dosis optimal probiotik berdasarkan bobot mutlak adalah $0,0036 \mathrm{ml} / \mathrm{l}$ dengan hasil bobot mutlak 26,00 g. Dosis optimal probiotik berdasarkan panjang mutlak adalah $0,0028 \mathrm{ml} / 1$ dengan hasil panjang mutlak $33,40 \mathrm{~cm}$. Kelangsungan hidup ikan nila tertinggi adalah $77 \%$ pada dosis probiotik $0,007 \mathrm{ml} / 1$.

Kata kunci: Probiotik, Ikan Nila, Laju Pertumbuhan, Kelangsungan Hidup, Bioflok

\section{Abstract}

Nile tilapia has a very important economic value for the community. Intensification of nile tilapia cultivation has an adverse impact on the environment. The high use of artificial feed causes pollution of the aquatic environment. One way to minimize the use of artificial feed is using biofloc system. This research aims to analyze the optimal dose of probiotics to the growth and survival rate of nile tilapia in biofloc systems. The method used is Randomized Complete Block Design (RCBD) using 4 treatments of probiotic doses and 3 replicates. The treatments are $\mathrm{P}_{1}(0.007 \mathrm{ml} / \mathrm{l}), \mathrm{P}_{2}(0.008 \mathrm{ml} / \mathrm{l}), \mathrm{P}_{3}(0.009 \mathrm{ml} / \mathrm{l})$, and Control $(0 \mathrm{ml} / \mathrm{l})$. Absolute weight, absolute length, and survival of nile tilapia are the main variables observed. The orthogonal polynomial analysis was used to determine the optimal dose of probiotics. The optimal dose of probiotics based on the absolute weight is 0.0036 $\mathrm{ml} / \mathrm{l}$ and it produces an absolute weight of $26.00 \mathrm{~g}$. The optimal dose of probiotics based on the absolute length of is $0.0028 \mathrm{ml} / 1$ and it produces an absolute length of $33.40 \mathrm{~cm}$. The highest survival rate for tilapia is $77 \%$ at probiotic doses of $0.007 \mathrm{ml} / 1$.

Keywords : Probiotics, Nile Tilapia, Growth Rate, Survival, Biofloc

\section{PENDAHULUAN}

Ikan nila merupakan salah satu spesies ikan budidaya terpenting di dunia. Dalam skala dunia total produksi ikan nila di Asia mencapai $72 \%$, Afrika sebesar 19 $\%$, dan Amerika $9 \%$ (FAO, 2012). Nila sebagai komoditas ikan mempunyai nilai ekonomi yang sangat penting. Nila mempunyai beberapa keunggulan, diantaranya mudah dibudidayakan dan disukai konsumen (Kordi, 2015).

Intensifikasi budidaya ikan nila menyebabkan dampak kurang baik terha- dap kelestarian lingkungan. Tingginya penggunaan pakan buatan pada budidaya intensif menyebabkan pencemaran lingkungan yang berasal dari sisa pakan dan kotoran (Asaduzzaman et al., 2008). Limbah pakan tersebut menyebabkan timbulnya ammonia. Kandungan ammonia dapat mencemari media air budidaya sehingga mengganggu pertumbuhan organisme budidaya (Kordi dan Andi, 2010).

Salah satu cara budidaya adalah dengan sistem bioflok yang dapat digunakan untuk budidaya ikan nila secara intensif. 
Hal tersebut dikarenakan ikan nila memiliki toleransi luas pada kepadatan tinggi dan kualitas air (Ombong, dan Indra, 2016). Pada budidaya ikan nila sistem bioflok dilakukan penambahan probiotik. Penambahan probiotik bertujuan mening-katkan pertumbuhan dan kelangsungan hidup ikan nila. Pada penelitian ini bertujuan mengoptimalkan penggunaan probiotik untuk meningkatkan laju pertumbuhan dan kelangsungan hidup ikan nila.

\section{METODOLOGI \\ Materi Penelitian}

Peralatan yang dibutuhkan yaitu ember 12 buah dengan diameter $30 \mathrm{~cm}$, tinggi $36 \mathrm{~cm}$, dan volume 25 liter. Peralatan pengambilan data yang digunakan yaitu timbangan digital, kamera, dan penggaris. Peralatan penunjang yang digunakan yaitu aerator, batu aerasi, selang, pipet ukur $1 \mathrm{ml}$, dan baskom. Peralatan pengukur kualitas air yang digunakan yaitu $\mathrm{pH}$ meter, $\mathrm{DO}$ meter, ammonia test kit, dan termometer. Bahan yang digunakan adalah benih ikan nila (Orechromis niloticus) ukuran 8-12 cm sebanyak 120 ekor, pakan pelet, probiotik Effective Microorganisme (EM4), dan molase.

\section{Rancangan Penelitian}

Penelitian ini menggunakan metode Rancangan acak kelompok (RAK) dengan 4 perlakuan dan 3 ulangan. Perlakuan dalam penelitian ini yaitu penambahan dosis probiotik pada $\mathrm{P}_{1}$ : $0,007 \mathrm{ml} / 1, \mathrm{P}_{2}$ : 0,008 $\mathrm{ml} / 1, \mathrm{P}_{3}: 0,009 \mathrm{ml} / \mathrm{l}, \quad$ dan $\mathrm{P}_{0}$ : tanpa probiotik (kontrol).

\section{Prosedur Kerja}

Wadah disiapkan dengan dibersihkan dan dijemur kemudian masing-masing diberi label, selanjutnya dilakukan pemasangan aerator untuk aerasi. Ikan uji yang digunakan berasal dari pedagang benih di Kecamatan Deket, Kabupaten Lamongan dengan ukuran 8-12 cm sebanyak 120 ekor. Ikan nila ditempatkan di dalam wadah untuk diaklimatisasi dan dipuasakan selama 1 hari.
Pada hari pertama, ember diisi dengan air dari kolam yang mengandung sisa-sisa pakan dan kotoran ikan. Kemudian ditambahkan probiotik EM4 sesuai dosis perlakuan dan mollase $0.25 \mathrm{ml} / \mathrm{l}$. Selanjutnya, media air didiamkan selama 710 hari. Benih ikan nila diukur panjang awal $\left(\mathrm{L}_{0}\right)$ dan ditimbang bobot awal $\left(\mathrm{W}_{0}\right)$. Kemudian benih ikan ditebar 10 ekor untuk tiap wadah. Setelah dilakukan penebaran benih, 2-3 hari kemudian ditambahkan probiotik sesuai dosis perlakuan dan mollase $0.25 \mathrm{ml} / 1$.

Perawatan benih ikan nila dilakukan selama 35 hari dan setiap 7 hari sekali diberikan probiotik sesuai dosis perlakuan dan molase $0.25 \mathrm{ml} / 1$. Setiap 7 hari diukur panjang dan bobotnya sebagai panjang akhir (Lt) dan bobot akhir (Wt). Selama penelitian, pakan diberikan dua kali sehari yaitu pagi dan sore hari, dengan dosis 3-4 \% dari bobot tubuh ikan. Pertumbuhan bobot mutlak ikan nila dihitung dengan menggunakan menurut Effendie (1979) yaitu :

Keterangan:

$$
\mathrm{W}=\mathrm{W}_{\mathrm{t}}-\mathrm{W}_{0}
$$

$\mathrm{W}=$ Pertumb

$\mathrm{Wt}=$ Bobot akhir $(\mathrm{g})$

$\mathrm{W}_{0}=$ Bobot awal $(\mathrm{g})$

Pengukuran panjang mutlak ikan nila dihitung dengan menggunakan rumus menurut Effendie (1979) yaitu :

$\begin{aligned} & \mathrm{L}= \\ & \text { Keterangan : }\end{aligned}$

$$
\mathrm{L}=\mathrm{L}_{\mathrm{t}}-\mathrm{L}_{0}
$$

$\mathrm{L}=$ Pertumbuhan panjang $(\mathrm{cm})$

$\mathrm{Lt}=$ Panjang akhir ikan $(\mathrm{cm})$

$\mathrm{L}_{0}=$ Panjang awal ikan $(\mathrm{cm})$

Kelangsungan hidup (SR) diukur dengan menggunakan rumus menurut Effendie (1979) sebagai berikut :

$$
\mathrm{SR}=\left(\frac{\mathrm{N}_{\mathrm{t}}}{\mathrm{N}_{0}}\right) \times 100 \%
$$

Keterangan:

$\mathrm{SR}=$ Kelangsungan hidup ikan (\%)

$\mathrm{Nt}=$ Jumlah ikan pada akhir penelitian

$\mathrm{N}_{0}=$ Jumlah ikan pada awal penelitian 


\section{Analisis Data}

Analisis data digunakan untuk melihat pengaruh penambahan dosis probiotik yang berbeda terhadap pertumbuhan dan kelangsungan hidup ikan nila. Variabel yang dianalisis adalah pengukuran bobot mutlak, panjang mutlak, dan kelangsungan hidup. Data penelitian dianalisis dengan metode one way ANOVA. Jika F Fitung $>$ $\mathrm{F}_{\text {table } 0.05}$ tetapi $<\mathrm{F}_{\text {tabel }} 0.01$ maka disimpulkan bahwa perlakuan dosis probiotik menunjukkan perbedaan nyata pada variabel yang diamati. Jika $F_{\text {hitung }}<\mathrm{F}_{\text {tabel }} 0.05$ maka disimpulkan bahwa perlakuan dosis probiotik tidak menunjukkan perbedaan nyata. Analisis data menunjukkan perbedaan nyata maka dilanjutkan dengan uji Beda Nyata Terkecil (BNT) 0.05. Penentukan nilai optimal dosis probiotik digunakan metode polynomial orthogonal.

\section{HASIL DAN PEMBAHASAN}

Tabel 1. Hasil uji Beda Nyata Terkecil (BNT) 0,05.

\begin{tabular}{ccccccc}
\hline & \multicolumn{2}{c}{ Bobot Mutlak } & \multicolumn{2}{c}{ Panjang Mutlak } & \multicolumn{2}{c}{ Kelangsungan Hidup } \\
Perlakuan & Rerata $(\mathrm{g})$ & Notasi & Rerata $(\mathrm{g})$ & Notasi & Rerata $(\mathrm{g})$ & Notasi \\
\hline $\mathrm{P}_{0}$ & 1,507 & $\mathrm{a}$ & 1,393 & $\mathrm{a}$ & 40,000 & $\mathrm{a}$ \\
$\mathrm{P}_{1}$ & 5,297 & $\mathrm{~b}$ & 2,577 & $\mathrm{~b}$ & 76,667 & $\mathrm{~b}$ \\
$\mathrm{P}_{2}$ & 3,703 & $\mathrm{ab}$ & 1,293 & $\mathrm{a}$ & 33,333 & $\mathrm{a}$ \\
$\mathrm{P}_{3}$ & 2,227 & $\mathrm{a}$ & 1,743 & $\mathrm{a}$ & 40,000 & $\mathrm{a}$ \\
$\mathrm{BNT}_{0,05}$ & 2,012 & & 0,722 & & 22,829 & \\
\hline
\end{tabular}

Keterangan : Angka-angka yang diikuti oleh huruf yang sama dalam satu kolom menunjukkan tidak berbeda nyata pada uji BNT 0,05 .

Dari hasil uji BNT 0,05 pada variabel bobot mutlak dihasilkan nilai BNT 0,05 sebesar 2,012. Perlakuan $\mathrm{P}_{1}$ berbeda nyata terhadap perlakuan $\mathrm{P}_{0}$ dan $\mathrm{P}_{3}$ tetapi tidak berbeda nyata terhadap perlakuan $\mathrm{P}_{2}$. Pada variabel panjang mutlak menghasilkan nilai BNT 0,05 sebesar 0,722. Perlakuan $\mathrm{P}_{1}$ berbeda nyata terhadap perlakuan $\mathrm{P}_{0}, \mathrm{P}_{2}$, dan $\mathrm{P}_{3}$. Pada variabel kelangsungan hidup dihasilkan nilai BNT 0,05 sebesar 22,829. Perlakuan $\mathrm{P}_{1}$ berbeda nyata terhadap perlakuan $\mathrm{P}_{0}, \mathrm{P}_{2}$, dan $\mathrm{P}_{3}$. Dari uji BNT 0,05 pada variabel bobot mutlak, panjang mutlak, dan kelangsungan hidup maka disimpulkan bahwa yang terbaik adalah pada perlakuan $\mathrm{P}_{1}$.

\section{Bobot Mutlak (g)}

Berdasarkan hasil penelitian, rata-rata peningkatan bobot mutlak ikan nila pada perlakuan $\mathrm{P}_{0}: 1,51 \mathrm{~g}, \mathrm{P}_{1}: 5,30 \mathrm{~g}, \mathrm{P}_{2}: 3,70$ $\mathrm{g}$, dan $\mathrm{P}_{3}: 2,23 \mathrm{~g}$. Bobot mutlak ikan nila tertinggi yaitu pada perlakuan $\mathrm{P}_{1}$ dengan penambahan dosis probiotik 0,007 $\mathrm{ml} / 1$ menghasilkan bobot mutlak sebesar 5,30 gram. Bobot mutlak ikan nila terendah ditunjukkan oleh perlakuan $\mathrm{P}_{0}$ yaitu tanpa penambahan probiotik. Pada perlakuan $\mathrm{P}_{0}$ menghasilkan bobot mutlak ikan nila sebesar 1,51 gram.

Menurut Widiyaningsih (2011), probiotik mampu memecah unsur nutrisi yang lebih sederhana, sehingga dapat membantu proses penyerapan nutrisi lebih baik. Peningkatan nutrisi akibat penambahan probiotik menghasilkan enzim exogenous seperti amilase, lipase, protease dan selulose. Enzim tersebut akan membantu enzim endogenous di inang untuk menghidrolisis pakan (Sahu et al., 2008).

Penentuan dosis probiotik optimal berdasarkan bobot mutlak ikan nila diketahui melalui analisis polynomial orthogonal. Hubungan antara perlakuan dosis probiotik dengan bobot mutlak ikan nila mempunyai nilai $\mathrm{R}^{2}=1$. Dari hasil tersebut, $100 \%$ bobot mutlak dipengaruhi oleh penambahan probiotik. 


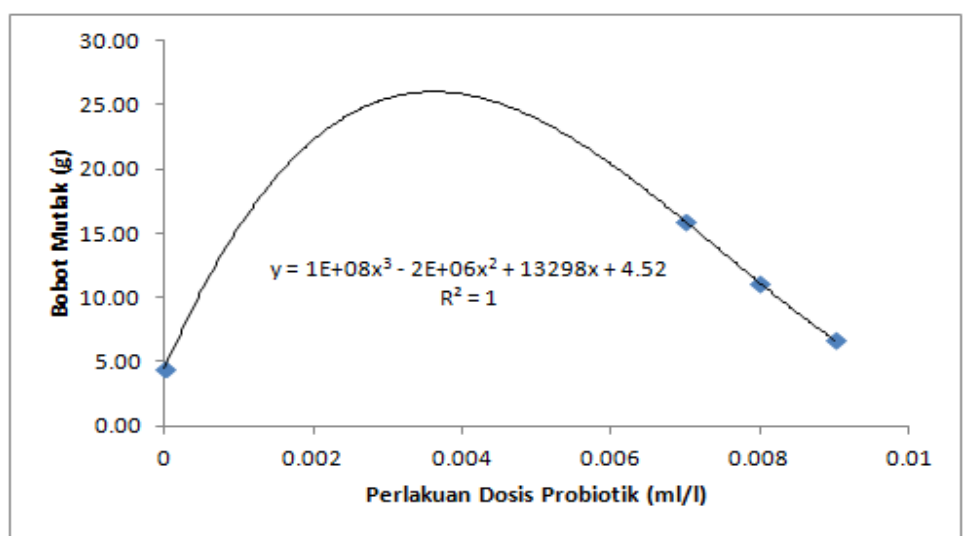

Gambar 1. Grafik polynomial orthogonal antara bobot mutlak dan perlakuan dosis probiotik $(\mathrm{ml} / \mathrm{l})$.

Berdasarkan grafik di atas, dosis optimal untuk bobot mutlak ikan nila adalah $0,0036 \mathrm{ml} / 1$ yang menghasilkan bobot mutlak ikan nila sebesar 26,00 g. Dari hasil uji BNT 0,05 dosis terbaik yaitu $0,007 \mathrm{ml} / 1$, tetapi setelah dilakukan uji polynomial orthogonal dosis tersebut merupakan titik penurunan bobot mutlak ikan nila. Dosis probiotik yang berlebihan melewati titik optimal $0,0036 \quad \mathrm{ml} / 1$ mengakibatkan penurunan bobot mutlak. Hal ini diduga akibat terlalu tingginya populasi bakteri yang bersifat aerob.

Tingginya populasi bakteri menimbulkan persaingan antar organisme dalam pemanfaatan nutrisi dan oksigen di dalam media air budidaya. Hal itu menyebabkan nutrisi dan oksigen di dalam media air tidak termanfaatkan dengan baik oleh ikan sehingga pertumbuhannya lambat. Menurut Ariyanti (2016), bakteri membutuhkan nutrisi, sumber energi dan kondisi ling- kungan tertentu untuk pertumbuhannya. Bakteri aerob adalah bakteri yang membutuhkan oksigen untuk partumbuhannya (Puspitasari et al., 2012).

\section{Panjang Mutlak (cm)}

Dari hasil penelitian, rata-rata panjang mutlak ikan nila pada perlakuan $\mathrm{P}_{0}$ : $1,39 \mathrm{~cm}, \mathrm{P}_{1}: 2,58 \mathrm{~cm}, \mathrm{P}_{2}: 1,29 \mathrm{~cm}$, dan $\mathrm{P}_{3}$ : $1,74 \mathrm{~cm}$. Panjang mutlak ikan nila tertinggi yaitu pada perlakuan $\mathrm{P}_{1}$ dengan penambahan dosis probiotik $0,007 \mathrm{ml} / 1$ menghasilkan panjang mutlak $2,58 \mathrm{~cm}$. Panjang mutlak terendah ditunjukkan pada perlakuan $\mathrm{P}_{2}$ dengan penambahan dosis probiotik $0,008 \mathrm{ml} / 1$ menghasilkan panjang mutlak $1,29 \mathrm{~cm}$. Penentuan dosis probiotik optimal berdasarkan panjang mutlak ikan nila dilakukan analisis polynomial orthogonal. Analisis polynomial orthogonal disajikan pada Gambar 2.

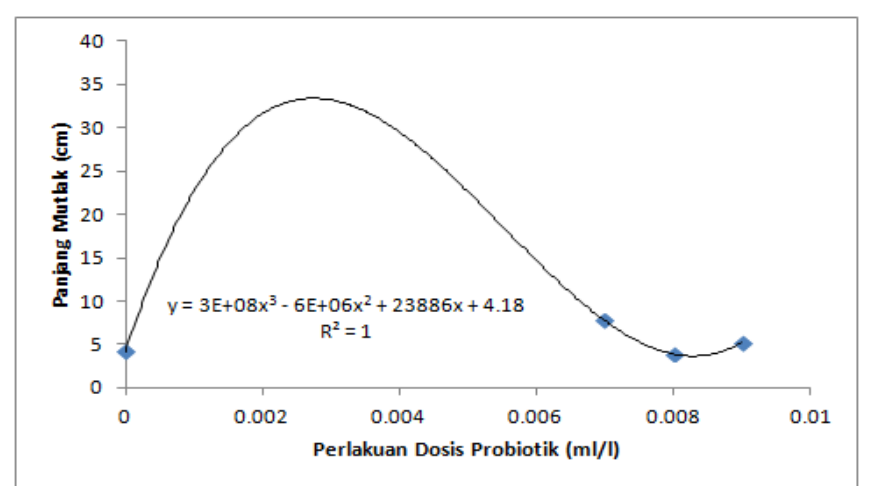

Gambar 2. Grafik polynomial orthogonal antara panjang mutlak dan perlakuan dosis probiotik $(\mathrm{ml} / \mathrm{l})$. 
Hubungan antara perlakuan dosis probiotik dengan panjang mutlak ikan nila mempunyai nilai $\mathrm{R}^{2}=1$. Dari hasil tersebut, $100 \%$ panjang mutlak dipengaruhi oleh penambahan probiotik. Dosis optimal untuk panjang mutlak ikan nila adalah $0,0028 \mathrm{ml} / 1$ menghasilkan panjang mutlak ikan nila sebesar 33,00 cm. Dari hasil uji BNT 0,05 dosis terbaik yaitu $0,007 \mathrm{ml} / 1$, tetapi setelah dilakukan uji polynomial orthogonal dosis tersebut merupakan titik penurunan panjang mutlak ikan nila.

Pertumbuhan meningkat jika pakan dapat dicerna dengan baik, sehingga menjadi energi yang dapat dimanfaatkan secara optimal oleh ikan. Penambahan probiotik dapat memperbaiki sistem pencernaan ikan sehingga mampu meningkatkan laju pertumbuhan secara optimal (Fitriyah, 2017).

\section{Kelangsungan Hidup Ikan Nila (\%)}

Berdasarkan hasil penelitian, rata-rata kelangsungan hidup ikan nila pada perlakuan $\mathrm{P}_{0}: 40 \%, \mathrm{P}_{1}: 77 \%, \mathrm{P}_{2}: 33 \%$, dan $\mathrm{P}_{3}: 40 \%$. Kelangsungan hidup ikan nila tertinggi yaitu pada perlakuan $\mathrm{P}_{1}$ dengan dosis probiotik $0,007 \mathrm{ml} / 1$ menghasilkan kelangsungan hidup $77 \%$. Kelangsungan hidup ikan nila terendah yaitu pada perlakuan $\mathrm{P}_{2}$ dengan dosis probiotik 0,008 $\mathrm{ml} / \mathrm{l}$ menghasilkan kelang-sungan hidup 33 $\%$. Menurut Yuniarti (2006), nilai kelangsungan hidup ikan nila yang baik berkisar antara 73,5 - 86,0 \%. Faktor penting yang mempengaruhi kelang-sungan hidup suatu organisme adalah asupan nutrisi pakan dan kualitas air (Kelabora, 2010).

\section{KESIMPULAN DAN SARAN Kesimpulan}

Dari hasil penelitian, dapat disimpulkan bahwa perlakuan dosis probiotik menunjukkan perbedaan nyata terhadap laju pertumbuhan ikan nila. Berdasarkan bobot mutlak ikan nila, nilai optimal dosis probiotik adalah $0,0036 \mathrm{ml} / \mathrm{l}$. Berdasarkan panjang mutlak ikan nila, nilai optimal dosis probiotik adalah $0,0028 \mathrm{ml} / 1$.
Selain itu, perlakuan dosis probiotik menunjukkan perbedaan nyata terhadap kelangsungan hidup ikan nila. Kelangsungan hidup ikan nila tertinggi adalah $77 \%$ pada penambahan dosis probiotik 0,007 $\mathrm{ml} / 1$.

\section{Saran}

Para pembudidaya ikan nila diharapkan mengoptimalkan penggunaan probiotik untuk memperoleh hasil maksimal. Pada penelitian selanjutnya diharapkan melanjutkan penelitian pada dosis probiotik yang mendekati titik optimal yaitu 0,0028 $\mathrm{ml} / \mathrm{l}$ dan $0,0036 \mathrm{ml} / \mathrm{l}$. Hal itu bertujuan untuk mencari titik optimal dosis probiotik yang dapat menghasilkan laju pertumbuhan maksimal.

\section{DAFTAR PUSTAKA}

Ariyanti, W., 2016. Pertumbuhan Bakteri E. colli dan Bacillus subtilis Pada Media Singkong, Ubi Jalar Putih, Dan Ubi Jalar Kuning Sebagai Substitusi Media NA [skripsi]. Surakarta : Universitas Muhammadiyah Surakarta.

Asaduzzaman, M., Wahab, M.A., Verdegem, M.C.J., Huque, S., Salam, M.A. and Azim, M.E., 2008. C/N Ratio Control and Substrate Addition for Periphyton Development Jointly Enhance Freshwater Prawn Macrobrachium rosenbergii Production in Ponds. Aquaculture, $280: 117-123$.

Effendie, M.I., 1979. Metode Biologi Perikanan. Yayasan Dewi Sri. Bogor. $112 \mathrm{hlm}$.

FAO., 2012. The State of World Fisheries and Aquaculture. FAO Fisheries and Aquaculture Department. Rome. Italy, $230 \mathrm{pp}$.

Fitriyah, U., 2017. Pengaruh Penambahan Probiotik Dengan Dosis Berbeda Pada Pakan Pellet Terhadap Pertumbuhan Ikan Nila (Oreochromis niloticus) [skripsi]. Gresik : Universitas Muhammadiyah Gresik. 
Kelabora, D.M., 2010. Pengaruh Suhu Terhadap Kelangsungan Hidup Dan Pertumbuhan Larva Ikan Mas (Cyprinus carpio). Berkala Perikanan Terubuk. 38 (1) : 71-81.

Kordi, K.M.G.H. dan Andi, B.T., 2010. Pengelolaan Kualitas Air Dalam Budidaya Perairan. Jakarta : Rineka Cipta. 210 hal.

Kordi, K.M.G.H., 2015. Akuakultur Intensif dan Super Intensif. Jakarta : Rineka Cipta : 424 hal.

Ombong, F. dan Indra, R.N.S., 2016. Aplikasi Teknologi Bioflok (BFT) Pada Kultur Ikan Nila (Oreochromis niloticus). Budidaya Perairan, 4(2) : 16-25.

Puspitasari, F.D., Maya, S. dan Nengah, D.K., 2012. Isolasi dan Karakteristik Bakteri Aerob Proteolitik dari Tangki Septik. Jurnal Sains dan Seni ITS, 1 (1) : 1-4.

Sahu, M.K., Swarnakumar, N.S., Sivakumar, K., Thangaradjou, T. and Kannan, L., 2008. Probiotics In Aquaculture : Importance and Future Perspectives. Indian J. Microbial, 48 : 299-308.

Widiyaningsih, E.N., 2011. Peran Probiotik Untuk Kesehatan. Jurnal Kesehatan, 4 (1) : 14-20.

Yuniarti, 2006. Pengaruh Kepadatan Benih Ikan Lele Dumbo (Clarias sp.) Terhadap Produksi Pada Sistem Budidaya dengan Pengendalian Nitrogen melalui Penambahan Tepung Terigu. [skripsi]. Bogor. Fakultas Perikanan dan Ilmu Kelautan, Institut Pertanian Bogor. 